\title{
Effects of Different $R$ ratios on Fatigue Crack Growth in Laser peened Friction Stir Welds
}

\author{
Omar Hatamleh ${ }^{1, \mathrm{a}}$, Lloyd Hackel ${ }^{2, \mathrm{~b}}$, Scott Forth ${ }^{3, \mathrm{c}}$
}

1) Structures \& Dynamics Branch, NASA-Johnson Space Center, Houston, Texas 77058

2) Metal Improvement Company, 7655 Longard Rd, Livermore, California 94551

3) Materials \& Processes Branch, NASA-Johnson Space Center, Houston, Texas 77058

aomar.hatamleh@nasa.gov ${ }_{2}$ bLloyd_hackel@mic.com, ${ }^{\text {c}}$ scott.c.forth@nasa.gov

Keywords: friction stir welding, laser peening, shot peening, fatigue crack growth

\begin{abstract}
The influence of laser peening on the fatigue crack growth behavior of friction stir welded (FSW) Aluminum Alloy (AA) 7075-T7351 sheets was investigated. The surface modification resulting from the peening process on the fatigue crack growth of FSW was assessed for two different $\mathrm{R}$ ratios. The investigation indicated a significant decrease in fatigue crack growth rates resulting from using laser shock peening compared with unpeened, welded and unwelded specimens. The slower fatigue crack growth rate was attributed to the compressive residual stresses induced by the peening.
\end{abstract}

\section{Introduction}

Friction stir welding (FSW) was invented by the Welding Institute in England in 1991 [1]. Since then, FSW has emerged as a promising solid state process with encouraging results, particularly when used on high strength aerospace aluminum alloys that are generally difficult to weld [2]. FSW transforms metals into a plastic state at a temperature below the melting temperature of the material, and then mechanically stirs the materials together, under pressure to produce high strength bonds.

Residual stresses developed during welding [3,4] can have a significant effect on the service performance of welded material with respect to fatigue properties, and fatigue crack growth process. Residual tension stresses commonly found in the heat-affected zone of friction stir welds can lead to faster crack initiation and propagation, reducing the advantages of the processes. Therefore, laser shock peening was investigated as a mean of moderating the tensile residual welding stresses in components.

Laser shock peening is a relatively new surface treatment technique that has been shown to be effective in improving the fatigue properties of a number of metallic materials $[5,6]$. Laser shock peening produces a compressive residual stress at the surface that can extend several $\mathrm{mm}$ or more deep into the material. Previous research $[7,8]$ has shown that the residual stress resulting from laser peening can be significantly higher and deeper than for conventional shot peening. Compressive stresses at the surface can significantly increase the fatigue life of applications where failure is caused by surface-initiated cracks..

Previous work [9] has demonstrated a substantial reduction in fatigue crack growth rates by utilizing the laser peening process. The data in the literature has focused on low stress ratios $(\mathrm{R}=0.1)$ because the affects of the compressive stresses will be most pronounced where crack closure is prevailing. In this study, the affects of the residual stresses from FSW and laser peening on fatigue crack growth rate are shown for both low and high stress ratios. Evaluating the high stress ratio $(\mathrm{R}=0.7)$ data will more clearly demonstrate the affects of the peening because closure affects will not be magnified by loading. 


\section{Experimental Procedure}

Two $6.35 \mathrm{~mm}$ thick 7075-T651 aluminum sheets were friction stir welded together in a butt configuration at the NASA Johnson Space Center. Following the welding process, the welded plates were aged from the T651 condition to the T7351 condition to prevent the welded material from continuing to age at room temperature. After heat treatment, the welded plates were inspected using radiographic and penetrant inspections to insure no voids or defects were present in the weld. Bending tests were also done on both the root and the crown sides of the weld to further evaluate the quality of the weld. The samples were inspected visually afterward with no crack indications revealed.

Before the laser shock peening process was applied, the specimens were milled on the top side of the weld removing about $0.4 \mathrm{~mm}$ of material. The surface of the specimens intended for peening were then covered with an aluminum tape $0.22 \mathrm{~mm}$ thick, which was replaced in between applications, or layers, of peening. A schematic of the laser peening process is illustrated in Figure 1. The tamping layer consisted of an approximately $1 \mathrm{~mm}$ thick laminar layer of flowing water. The laser peening was applied using a square laser spot size of $4.72 \times 4.72 \mathrm{~mm}^{2}$ with a laser power density of $4 \mathrm{GW} / \mathrm{cm}^{2}$ and $18 \mathrm{~ns}$ in duration. Three layers of laser were used to peen the specimens. The spots within a layer were overlapped 3\%. Peening between layers had an off-set of 33\% in the two in plane directions. Both sides of the specimen were shocked using the same conditions. All laser peening was performed at the Metal Improvement Company in Livermore, California.

After the peening process, a $12.5 \mathrm{~mm}$ wide through thickness starter crack was introduced at $7.5 \mathrm{~mm}$ from the edge of the weld, corresponding to the location of the Heat Affected Zone (HAZ) shown in Figure 2, using an electric discharge machine (EDM). The HAZ location corresponded to the highest tensile residual surface stress according to x-ray diffraction measurements. The dimensions and crack location are shown in the inset of

Figure 3. The fatigue testing was performed under constant amplitude axial loading using a servo-hydraulic machine. The crack length was measured using the direct current potential difference method. All fatigue crack growth (FCG) specimen measurements were carried out at constant amplitude loads in room temperature laboratory air at a frequency of $22 \mathrm{~Hz}$, and at stress ratios, $\mathrm{R}$ of 0.1 and 0.7 .

\section{$3 \quad$ Results and discussion}

\subsection{Weld microstructure}

Figure 2 illustrates the cross section of the weld showing the transition from the nugget- Thermo Mechanical Affected Zone (TMAZ)-HAZ microstructure on the retreating area of the weld. Relative to the nugget, the TMAZ experienced less plastic deformation and lower temperatures. The grain structure in this region was elongated, with some considerable distortions that may be attributed to mechanical action from the welding tool. The HAZ was unaffected by mechanical effects from the tool, and had a grain structure similar to the parent material grain structure. Previous work by Jata et al [10] has indicated that strengthening precipitates in the HAZ region had grown in size and were several times larger than in the parent material. 


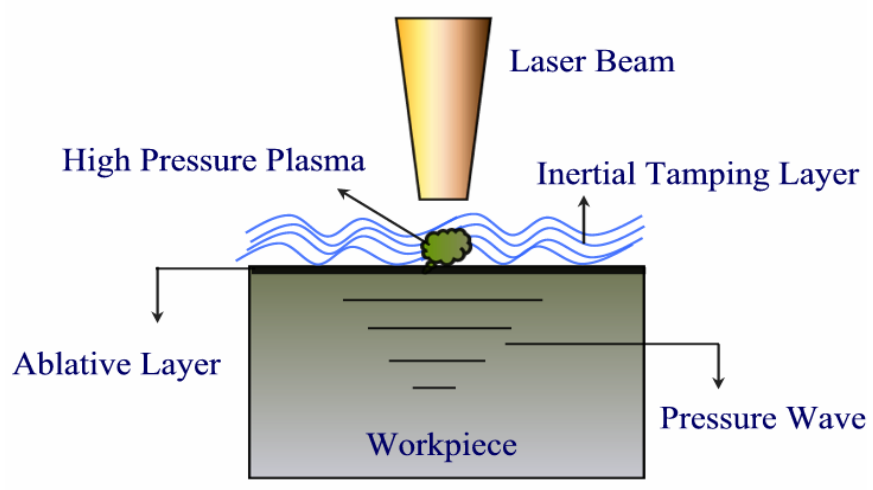

Figure 1 Laser peening process

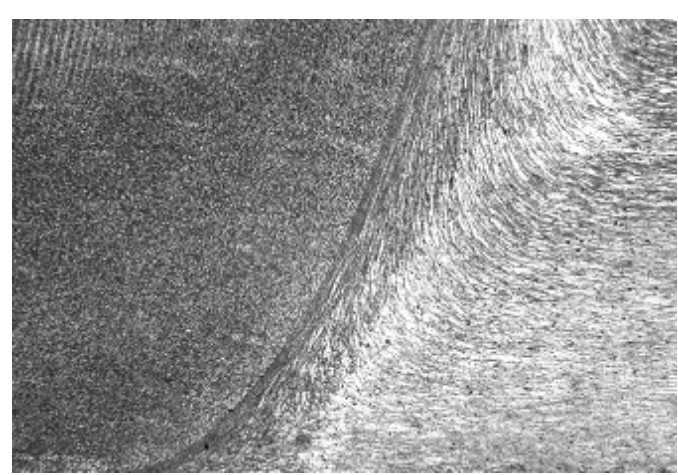

Figure 2 A section of the weld nuggetTMAZ-HAZ interface

\subsection{Fatigue Crack Propagation}

Figure 3 compares the fatigue crack growth rates for laser peened welded, aswelded, and baseline (parent material) specimens. The data is presented for two stress ratios, $\mathrm{R}=0.1$ and 0.7 . Unfortunately, data was not generated on the as-welded at $\mathrm{R}=$ 0.7. Examining first the $\mathrm{R}=0.1$ data, the friction stir welding induced a residual tensile stress, increasing the crack growth rate at a given $\Delta \mathrm{K}$ over the baseline data. The application of the laser shock peening to the welded specimens significantly reduced the crack growth rate, even below that of the baseline data. The differences in the data sets are pronounced at low $\Delta \mathrm{K}$ values because of the increase in crack closure from the peening compressive residual mean stress or conversely a decrease in crack closure due to weld tensile residual stress. At higher $\Delta \mathrm{K}$ values, the difference is less pronounced because the as crack increases in length, the residual stresses are relaxed, also reported in Galatolo et al [11].

Examining the $\mathrm{R}=0.7$ data shows a similar trend as the $\mathrm{R}=0.1$ data set. The application of laser shock peening to the friction stir welded samples completely wiped out the tensile residual stress from welding with the compressive residual stress from peening. In this case, the compressive residual mean stress had a significant effect on growth rates at the higher $\Delta \mathrm{K}$ values. The $\mathrm{R}=0.7$ data generated by Forth, et al [12] becomes unstable at a $\Delta \mathrm{K}$ value of $8 \mathrm{MPa} \mathrm{m}^{1 / 2}$, whereas the peened data is still stable at a $\Delta \mathrm{K}$ of $13 \mathrm{MPa}$ $\mathrm{m}^{1 / 2}$. The compressive stress drives the maximum stress intensity below the cyclic fracture toughness for an applied stress ratio of 0.7 . For the $\mathrm{R}=0.7$ data presented herein, the laser shock peening has a significant, beneficial affect on the crack growth rate for any given $\Delta \mathrm{K}$. 


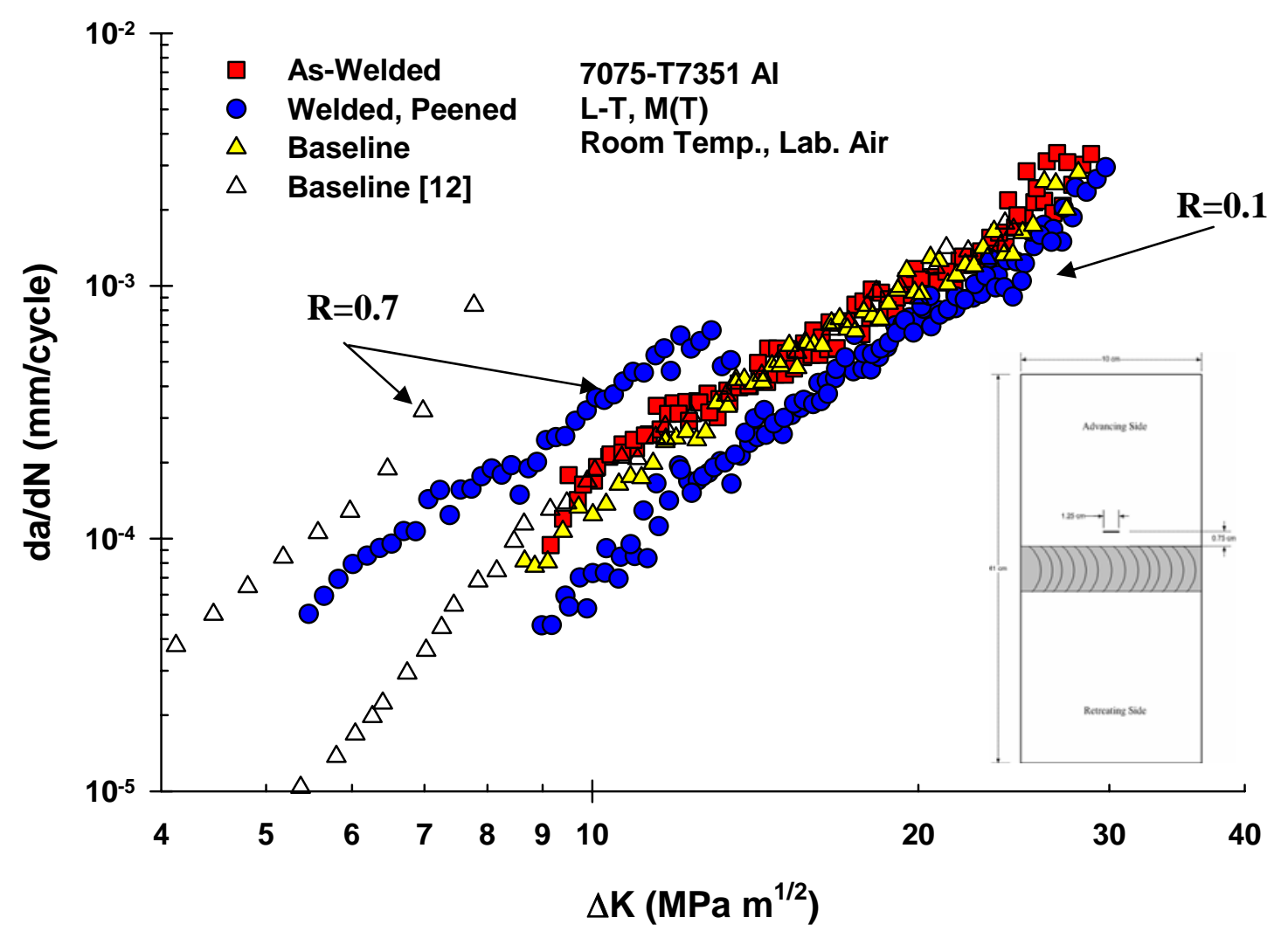

Figure 3 Fatigue crack growth rates FSW 7075-T7351

\section{Summary}

The surface modification from laser shock peening was used to introduce compressive residual stresses into friction stir welded AA 7075-T7351 specimens. The fatigue behavior was determined by measuring the fatigue crack length versus the number of cycles for several conditions. The influence of peening on the fatigue crack growth rate was characterized and evaluated for two different applied stress ratios. The three layer laser shock peening applied to friction stir welded specimens resulted in a substantial reduction in fatigue crack growth rate compared to the as-welded data. The peened data even showed an improvement over the base unwelded material for both stress ratios of 0.1 and 0.7 . Therefore, the application of laser shock peening to friction stir welded specimens improves the fatigue crack growth performance to the baseline or better regardless of applied stress ratio.

\section{References}

1 Thomas W. M et al. Friction stir butt welding. Int Patent App PCT/GB92/02203, and GB Patent App 9125978.8, December 1991. US patent No. 5, 460,317, October 1995

2 J. Q. Sue at al. Microstructural investigation of friction stir welded 7050- T651 aluminum. Acta Materialia 51 (2003) 713-729 
3 Mishra R. S. et al. Friction Stir Welding and Processing. Materials Science and Engineering R 50 (2005) 1-78.

4 Donne, C. D. et al. Investigations on Residual Stresses in Friction Stir Welds. 3'rd International Symposium on Friction Stir Welding, Kobe, Japan 2001.

5 J. M. Yang at al. Laser shock peening on fatigue behavior of 2024-T3 Al alloy with fastener holes and stopholes. Materials Science and Engineering A298 (2001) 296-299

6 C. Rubio-Gonzalez et al. Effect of laser shock processing on fatigue crack growth and fracture toughness of 6061-T6 aluminum alloy. Materials Science and Engineering A 386 (2004) 291-295

7 C. Montross et al. Laser shock processing and its effects on microstructure and properties of metal alloys: a review. International Journal of Fatigue 24 (2002) 1021-1036

8 P. Peyre at al. Laser shock processing of aluminium alloys. Application to high cycle fatigue behaviour. Material Science and Engineering A210. (1996) 102-113

9 O. Hatamleh et al. Laser and Shot Peening Effects on Fatigue Crack Growth in Friction Stir Welded 7075-T7351 Aluminum Alloy Joints. International Journal of Fatigue. Volume 29, Issue 3 , March 2007, Pages 421-434.

10 Jata K et al. Metall Materials Transactions. 2000, 31A. 2181-2192.

11 Galatolo R. et al. Fatigue crack propagation in residual stress fields of welded plates. International Journal of Fatigue. Vol. 19, No 1, pp 43-49, 1997.

12 S. Forth et al. Experimental and computational investigation of three dimensional mixedmode fatigue. Fatigue Fract. Engng. Mater. Struct., Vol. 25, pp. 3-15, 2002. 